\title{
ASPIRE Aerodynamic Models and Flight Performance
}

\author{
Suman Muppidi \\ AMA Inc., NASA Ames Research Center, Moffett Field, CA 94085, USA \\ Clara O’Farrell \\ Jet Propulsion Laboratory, California Institute of Technology, Pasadena, CA 91109, USA \\ John W Van Norman \\ AMA Inc., NASA Langley Research Center, Hampton, VA 23681, USA \\ and \\ Ian G Clark \\ Jet Propulsion Laboratory, California Institute of Technology, Pasadena, CA 91109, USA
}

\begin{abstract}
NASA's Advanced Supersonic Parachute Inflation Research Experiments (ASPIRE) project was established to test full-scale supersonic parachutes at Mars-relevant conditions, as a risk-reduction activity for NASA's upcoming Mars2020 mission. Deployment and inflation of Disk-Gap-Band (DGB) parachutes were examined at Mach number and dynamic pressure conditions relevant to Mars2020, using a sounding rocket platform. The flight tests examined two parachutes: a build-to-print version of the parachute used by the Mars Science Laboratory and a strengthened version of this parachute that has the same geometry but differs in materials and construction. The first flight test (SR01) of the built-to-print parachute took place on October 4, 2017, followed by the first test of the strengthened parachute during flight SR02 on March 31, 2018. A second test of the strengthened parachute with a higher target load, SR03, took place on September 7, 2018. Over the sequence of the three tests, the parachute was exposed to increasing aerodynamic loads with the peak load during SR03 being significantly larger than is expected during a Martian descent. All three tests were successful: the parachute deployment and inflation occurred at the intended conditions, the measurement systems performed as designed and provided the data, and the parachutes survived the aerodynamic loads they were exposed to. The flight tests yielded valuable data on parachute forces and high-speed imagery of the deployment and inflation process.
\end{abstract}

The final paper will provide details of the aerodynamic behavior and performance of the parachute over the three tests, along with comparisons to pre-flight predictions.

\section{Introduction}

S ince 1976, all the United States missions to the surface of Mars have used a variant of the Disk-Gap-Band (DGB) parachute developed for the twin Viking landers ${ }^{1}$. The design and development of the DGB for Viking was aided by a series of campaigns during the 1960s including wind tunnel testing, low and high altitude drop testing, and high altitude supersonic tests ${ }^{2,3,4,5,6}$. Following Viking, multiple NASA missions to Mars successfully deployed a DGB during the descent phase, including Mars Pathfinder in 1997, Mars Polar Lander in 1999, the Mars Exploration Rovers in 2004, Phoenix lander in 2007, and the Mars Science Laboratory in 2012. A comprehensive review of the decelerators is provided in Cruz \& Lingard ${ }^{7}$.

Recently, NASA's Low-Density Supersonic Decelerators (LDSD) project has conducted supersonic, highaltitude tests of two large parachutes for planetary exploration ${ }^{8,9}$. The parachutes, which were $30.5 \mathrm{~m}$ in nominal diameter, were variants of the supersonic Ringsail parachute. During supersonic testing at Mach numbers above 2.0, both parachutes experienced catastrophic failure at or near full inflation, at loads well below those the parachute had been successfully tested to in subsonic low-altitude testing. In addition, scientific cameras on board the LDSD test vehicle revealed an asymmetric and dynamic deployment and inflation process. The findings of the LDSD project 
have highlighted the need for supersonic, high-altitude testing of parachutes of the scale and materials necessary for future missions to Mars.

The Advanced Supersonic Parachute Inflation Research and Experiments (ASPIRE) project was established in 2016 to study the deployment, inflation, and performance of 21.5-m DGBs in supersonic, low-density conditions. Two test articles were deployed: a full-scale version of the parachute used by the Mars Science Laboratory (MSL), and a full-scale strengthened version of this parachute which has the same geometry but differs in materials and construction. The parachutes were delivered to targeted deployment conditions representative of flight at Mars by sounding rockets launched out of NASA's Wallops Flight Facility (WFF). The first set of tests (SR01) occurred on 4th October 2017. The parachute was successfully deployed and inflated at about Mach 1.77, at an altitude of $42 \mathrm{~km}$. The payload, and the inflated parachute, descended slowly and splashed into the ocean approximately 32 minutes after inflation. Figure 1 shows a schematic of the flight test including the timing of significant events and some important trajectory parameters. Also shown (in red) are the expected range of these parameters. For example, prior to the flight test the apogee altitude was expected to be between 42.4 and $60.2 \mathrm{~km}$; the apogee during the flight test was at an altitude of $51.0 \mathrm{~km}$. The second flight test (SR02) took place on March 31 2018 , where the apogee was $54.8 \mathrm{~km}$ and the parachute deployment was at Mach 1.97. During the third flight test (SR03) on September 72018 , the parachute was deployed at a Mach number of 1.85 and a dynamic pressure of $932 \mathrm{~Pa}$ (significantly higher than that during SR01, as shown in figure 01).

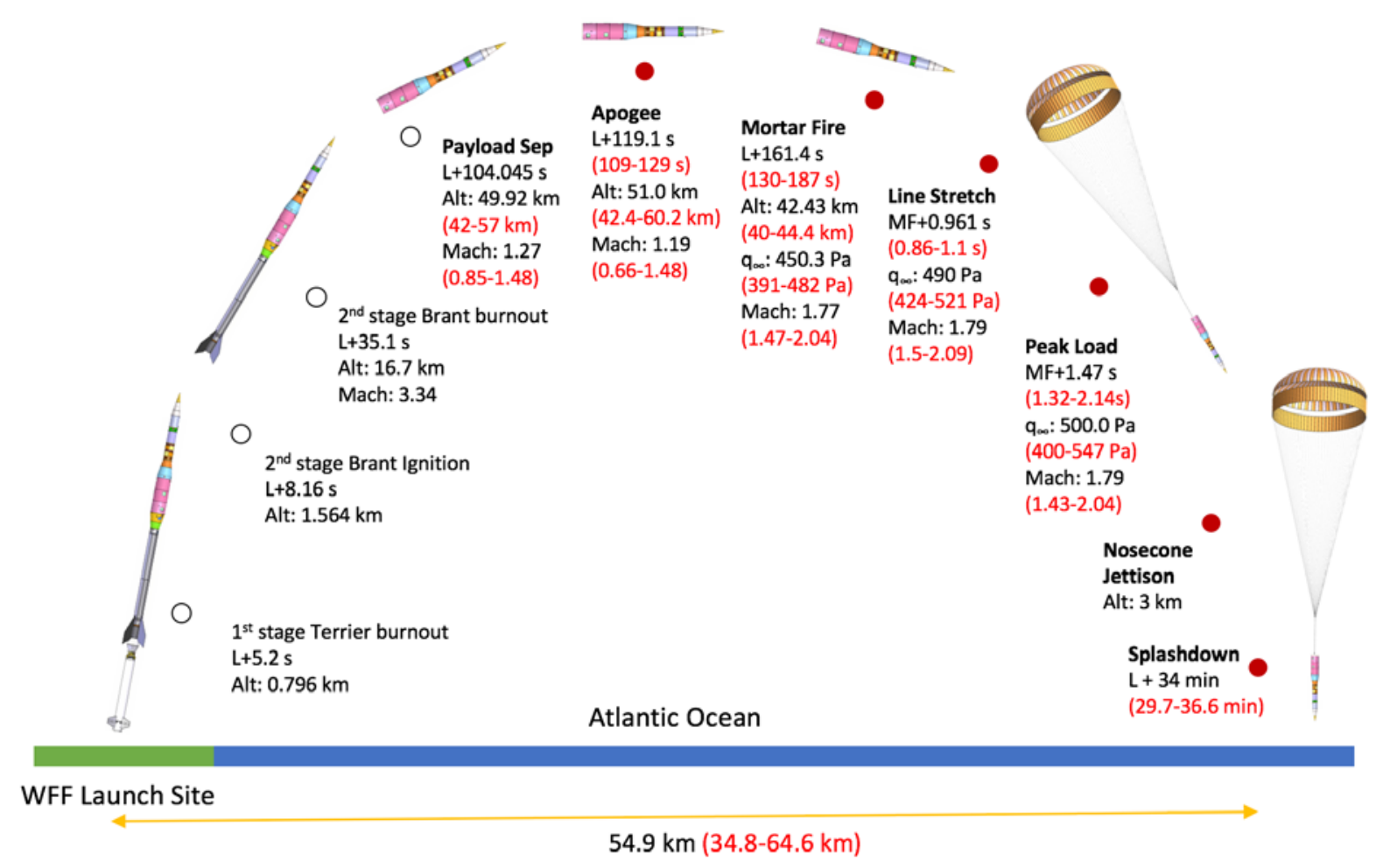

Figure 1 Schematic of the Flight test shows launch, delivery of the payload, parachute deployment and splashdown. The parameters in red show the expected range pre-flight, and the corresponding black text show the actual values during the first flight test SR01 (4 $4^{\text {th }}$ October 2017).

In designing the flight tests, detailed flight mechanics simulations are used to evaluate payload trajectory, determine the correct trigger (that results in the parachute deployment at desired conditions), predict the parachute loads, estimate the splash-down footprint in the ocean, etc. Aerodynamic models for the slender body payload and the parachute, along with reasonable dispersions, are necessary inputs to these simulations. Computational Fluid Dynamics (CFD) simulations of subsonic and supersonic flow past the slender body was used to generated an aerodynamic database, which in turn helped predict its trajectory prior to parachute inflation. The final paper will describe the generation of this database and compare pre-flight predictions to post-flight reconstruction.

Modeling the performance of a supersonic parachute in the wake of a slender forebody is more difficult, and there is limited test data available. The lack of historical test data (of similarly sized parachutes behind thin/slender

American Institute of Aeronautics and Astronautics 
bodies inflated at desired supersonic conditions) caused the ASPIRE aerodynamics team to rely on performance of parachutes behind blunt bodies (such as that during the descent of MSL in 2012) and account for the differences in the leading body geometry ${ }^{15}$. The final paper will provide reconstructed trajectory and the parachute performance from the three sounding rocket tests. The differences and similarities between the three tests will be presented, along with comparisons between pre-flight predictions and flight test data. Finally, the paper will suggest modifications to the models.

\section{ASPIRE Payload Aerodynamics Model}

The ASPIRE payload section carries the experiment (including the packed parachute and instrumentation) and is designed to provide sufficient ballast to satisfy the infinite mass assumption for parachute inflation and deceleration. As shown in Figure 1, its basic configuration consists of a conical nose cone with $9.5^{\circ}$ half angle and $0.4384 \mathrm{~m}$ base diameter, followed by a cylindrical section, a conical transition to $0.7239 \mathrm{~m}$ diameter, and a second cylindrical section with a flat base. The overall length of the payload is $6.6606 \mathrm{~m}$ and its mass including the MSL parachute is 1176.8 $\mathrm{kg}$. As typical of slender bodies, ASPIRE payload aerodynamics are sensitive to viscosity; at low angles of attack, the viscous contribution to ASPIRE's drag can exceed $20 \%$. This is in marked contrast to the aerodynamic behavior of blunt bodies (such as the M2020 capsule) where the viscous contributions are far lower, and the drag coefficient in turbulent and laminar flows is almost the same.

The ASPIRE payload aerodynamic model was constructed for use by the flight dynamics team in targeting flight conditions and predicting the flight performance, and is comprised of tabulated aerodynamic coefficients and aerodynamic uncertainties. The model is invoked to calculate static aerodynamic coefficients for a given set of input arguments (instantaneous center of gravity $(\mathrm{cg})$ location, freestream Mach number, angles of attack and sideslip, and uncertainty dispersions).

Static aerodynamic coefficients for the ASPIRE payload were predicted using NASA-developed computational fluid dynamic (CFD) codes, where the OVERFLOW solver was used for production runs, and the FUN3D and DPLR codes were used for code-to-code comparisons and point checks. No pitch damping model was implemented, as none was deemed appropriate for ASPIRE's natural pitch cycle rate at nominal flight conditions ( $<<1 \mathrm{~Hz}$ ). The simulations spanned a Mach number range of 0.9 to 2.45 , and at total angles of attack $\alpha_{T}=0,2,5,10,15,20,30,45,60$, and $75^{\circ}$ to cover possible off-nominal flight scenario.
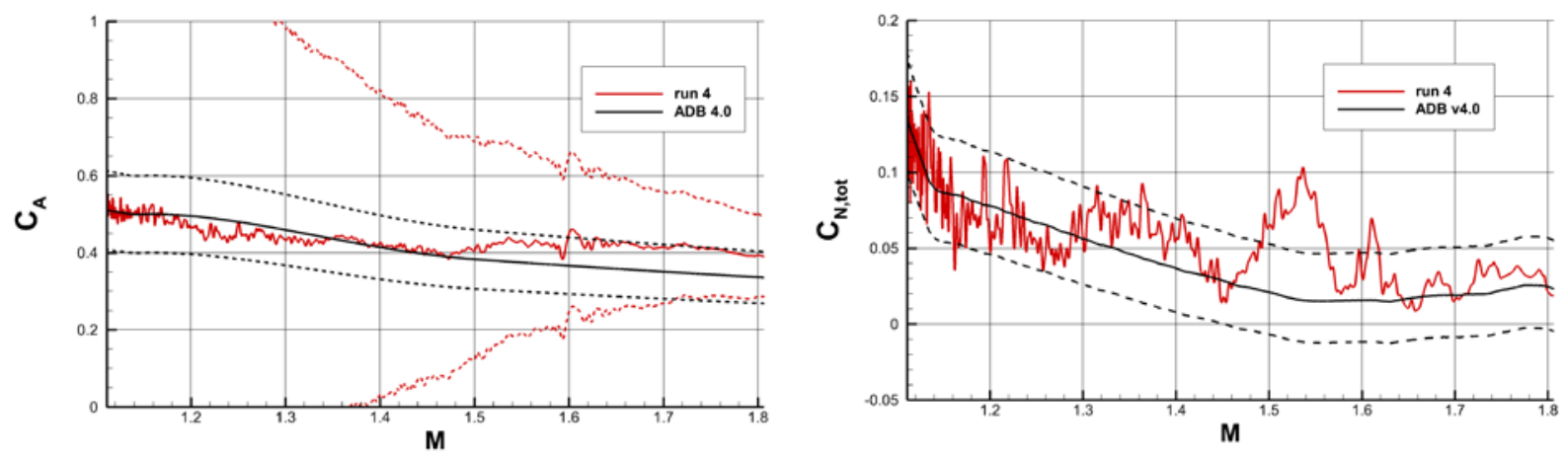

Figure 2 Reconstructed axial and normal force coefficients (red) on the ASPIRE payload during the third flight test SR03 compared to the pre-flight predictions (in black) along with the uncertainties in the model.

Figure 2 compares the axial and normal force coefficients on the payload from the third flight test (SR03) prior to parachute deployment. The figure also shows pre-flight model predictions and the associated uncertainties. Overall, the comparison is reasonable with a few excursions in $C_{N}$ which exceed the predicted uncertainty band. 


\section{ASPIRE Parachute Drag Model}

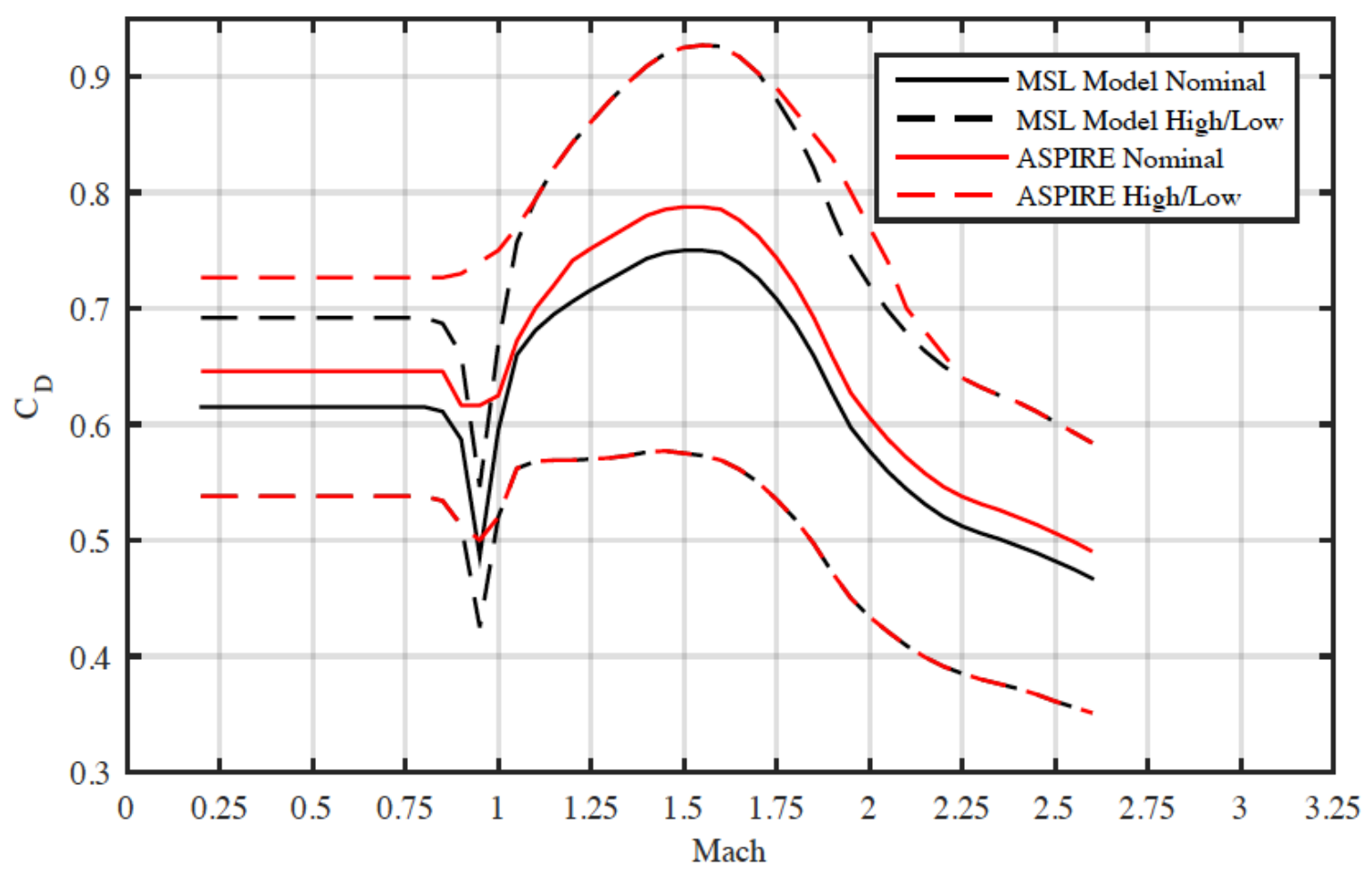

Figure 3 ASPIRE drag model, along with the MSL model that it is based on. Note that the lower bound is unchanged and the nominal drag is higher than the MSL.

The drag model for ASPIRE (figure 3) was based on the MSL drag model, but updated to account for the difference in the leading body (slender body vs blunt body). This update was informed by the available test results (flight tests and wind tunnel tests) and numerical simulations. Available wind tunnel data at subsonic speeds indicated that DGBs behind slender body exhibited a drag higher than those behind blunt bodies, by about $1-11 \%$. As a result, the nominal ASPIRE drag model and the upper bound curve (for subsonic speeds) was increased by about $5 \%$ from the baseline MSL drag model. At supersonic speeds, the slender body wind tunnel tests showed a higher drag (compared to blunt leading bodies) by 6-11\%. These differences were consistent with CFD simulations of flow past simplified/rigid canopies. As a result, the nominal ASPIRE drag model was increased by $5 \%$ compared to the MSL nominal drag model. The development of the parachute drag model, along with the details of the simulations that helped to inform the effects of drag on the leading body geometry were detailed in reference 15. 


\section{ASPIRE Flight Tests}

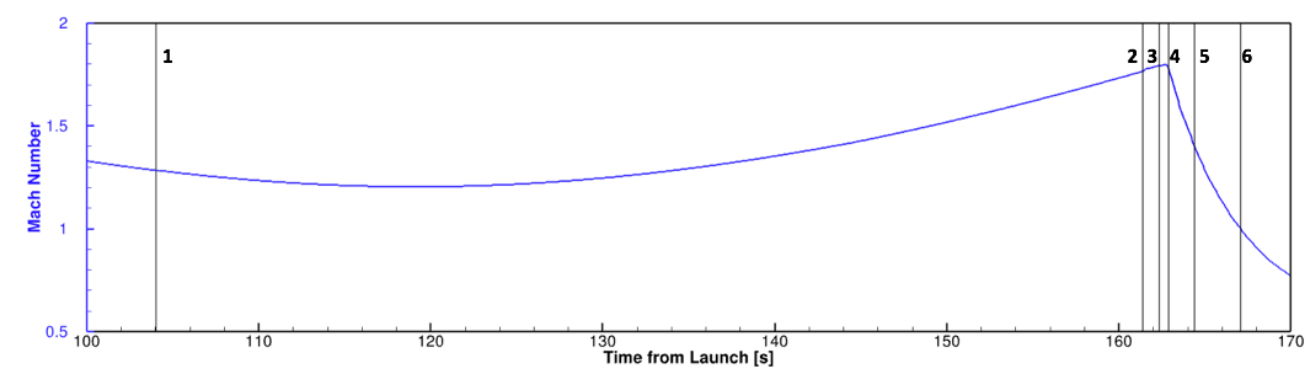

Events Marked

1. Black Brant Separation

2. Mortar fire

3. Parachute Line Stretch

4. Parachute Peak Load

5. Mach 1.4

6. Mach 1.0
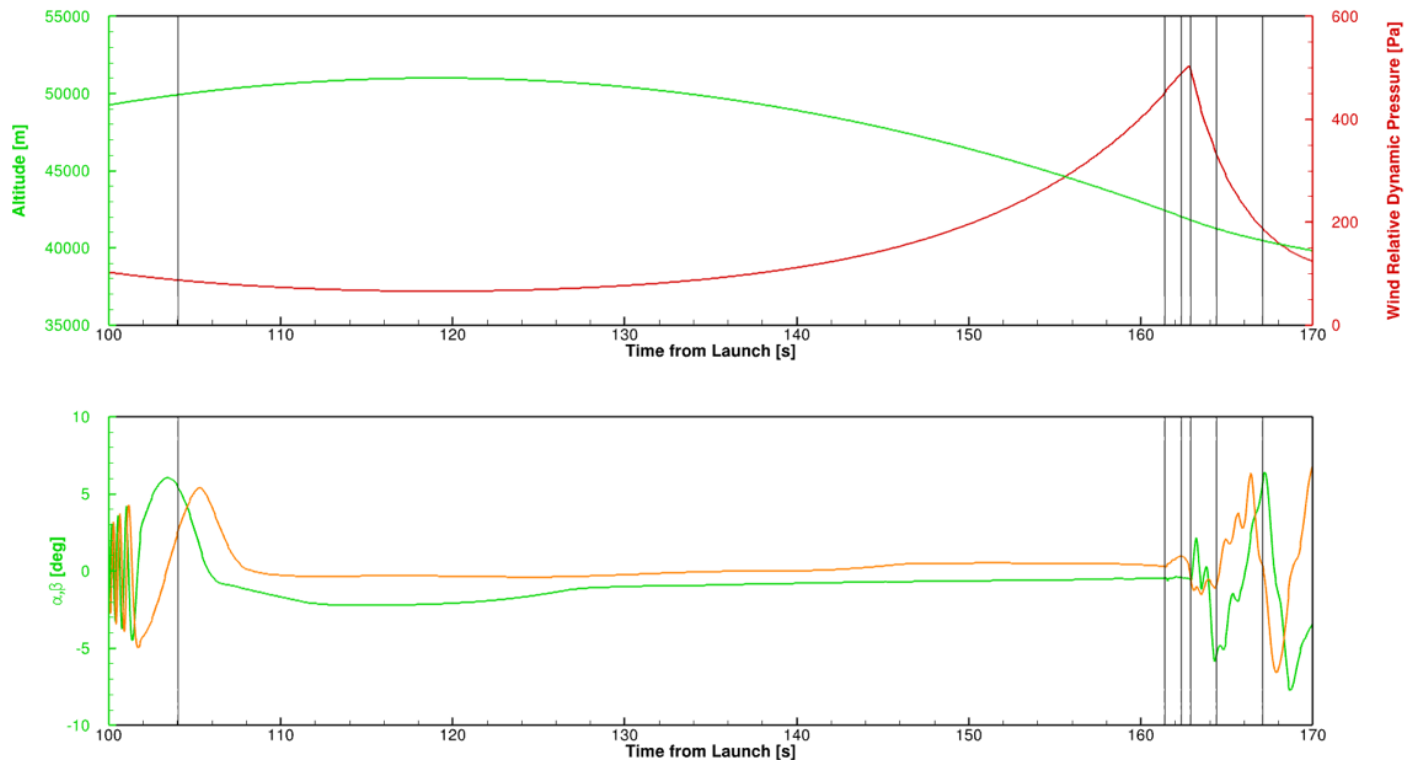

Figure 4 Trajectory during the first flight test (SR01). Figures show the variation of Mach number, altitude, attitude and dynamic pressure leading up to and just past parachute inflation.

The first flight test (SR01) occurred on $4^{\text {th }}$ October $2017^{13}$. The two-stage sounding rocket delivered the payload (containing the parachute and the instrumentation) to an altitude of roughly $50 \mathrm{~km}$. Past the apogee $(51.00 \mathrm{~km})$, as the payload was accelerating back towards the Earth, the parachute deployment commenced via mortar fire at an altitude of $42.4 \mathrm{~km}$ and a dynamic pressure of $452.5 \mathrm{~Pa}$. The parachute pack sails away from the payload and about a second later, parachute line stretch occurred. The parachute peak load was attained another half-second later. The payload delivery and parachute deployment occurred at the targeted conditions (as defined by the Mach number and dynamic pressure), and the test provided imagery and parachute loads. Figure 4 shows the trajectory of the flight including payload separation and parachute deployment. Figure 5 shows images from one of the high-speed, highresolution cameras on the payload photographing the parachute. Reference 13 presents a comprehensive overview of the flight test, additional imagery, and atmospheric information that is relevant to post-flight reconstruction. During this flight test, the parachute experienced a peak aerodynamic force of about 31,000 lbf.

The second flight test (SR02) occurred on March $312018^{14}$. Here, the payload separated from the Black Brant second stage at an altitude of $53.0 \mathrm{~km}$ and reached an apogee of $54.8 \mathrm{~km}$ before accelerating back towards the surface of the Earth. The parachute deployment sequence was initiated at a $40.77 \mathrm{~km}$ altitude and a Mach number of 1.97 (dynamic pressure of $670.63 \mathrm{~Pa}$ ) resulting in a peak parachute load of 50,900 lbf. The third flight test (SR03), on September $7^{\text {th }}$ 2018, targeting an even higher force on the parachute, initiated the parachute deployment sequence at a dynamic pressure of $931 \mathrm{~Pa}$ (Mach number 1.85, altitude $38.1 \mathrm{~km}$ ) resulting in a peak parachute load of 67,400 lbf. 


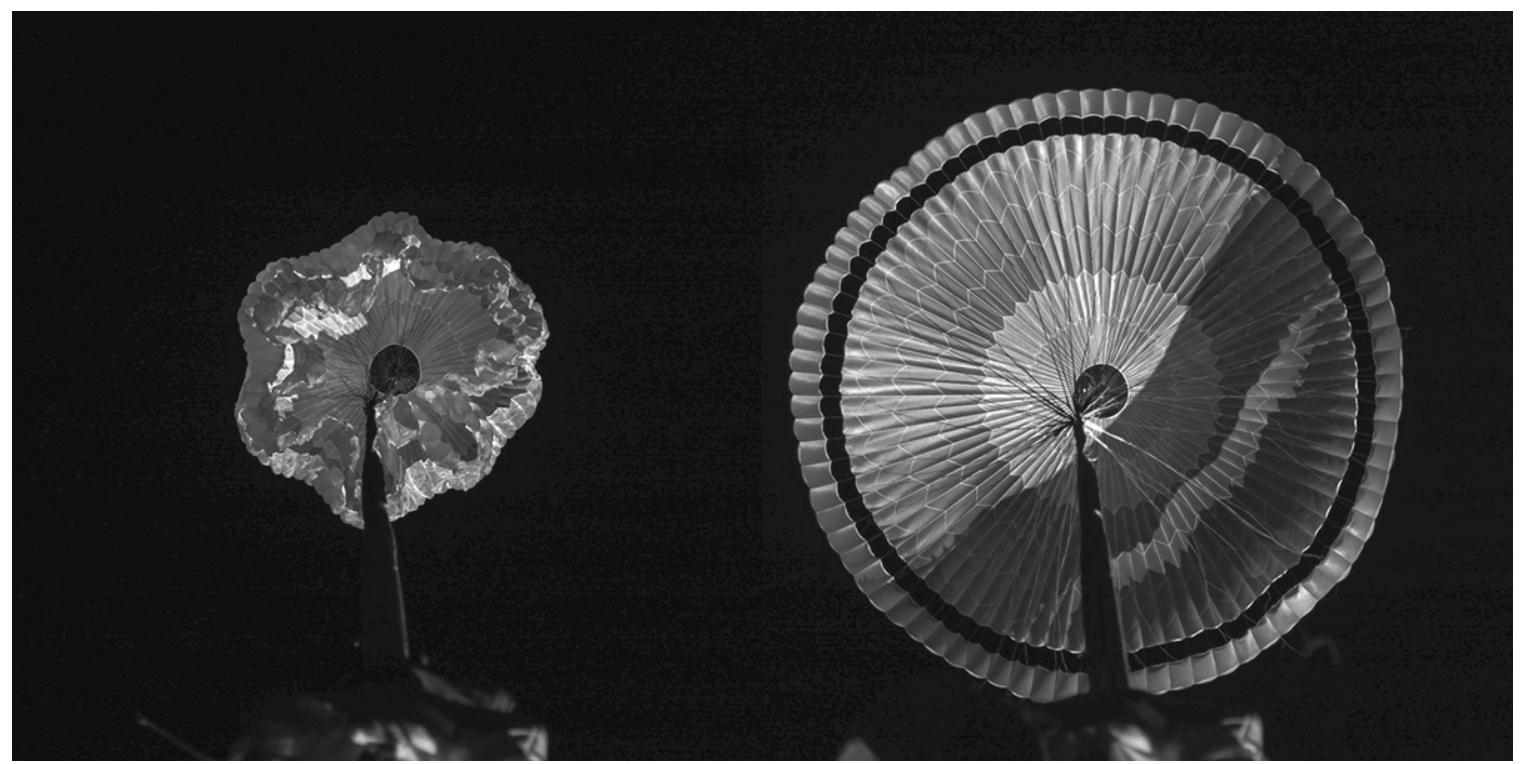

Figure 5 Images from a high-speed camera on the payload show the parachute as it inflates during SR01. Images such are these will be used for parachute position and shape reconstruction, and to understand parachute inflation dynamics.

\section{Final Paper}

Currently, the ASPIRE team is performing analysis, documentation and dissemination of the data from the three flight tests. Part of the analysis involves comparison of all of the pre-flight assumptions and predictions - including the payload aerodynamic predictions, the parachute deployment and inflation models, the parachute drag model and the static aerodynamics of the parachute.

The final paper will present detailed trajectories of the payload during freeflight and soon after parachute inflation (such as shown in figure 4) with emphasis on differences between the three flights and/or any discrepancies. The paper will use these trajectories and measurements from the on-board accelerometers to compare the pre-flight payload aerodynamic predictions to the post-flight reconstruction. The paper will also present the parachute performance (drag, stability) during the three flights along with comparisons to pre-flight predictions. All of the data will be used to suggest corrections to models for any future applications.

\section{Acknowledgments}

This research was carried out at the Jet Propulsion Laboratory, California Institute of Technology, under a contract with the National Aeronautics and Space Administration. Suman Muppidi and John W. Van Norman are funded by NASA contracts NNA15BB15C and NNL12AA09C to AMA Inc., respectively.

\section{References}

${ }^{1}$ Cooley, C. G., and Lewis, J. G., “Viking 75 Project: Viking Lander System Primary Mission Performance Report,” Tech. Rep. CR-145148, Apr 1977.

${ }^{2}$ Bobbitt, P. J., Mayhue, R. J., Faurote, G. L., and Galigher, L. L. “Supersonic and SubsonicWind-Tunnel Tests of Reefed and Unreefed Disk-Gap-Band Parachutes,” Tech. Rep. 1970-1172, 1970.

${ }^{3}$ Jaremenko, I., Steinberg, S., and Faye-Petersen, R., "Scale Model Test Results of the Viking Parachute System at Mach Numbers From 0.1 Through 2.6,” Tech. Rep. CR-149377, 1971.

${ }^{4}$ Eckstrom, C. V., and Preisser, J. S., “ Flight Test of a 30-Foot-Nominal-Diameter Disk-Gap-Band Parachute Deployed at a Mach Number of 1.56 and a Dynamic Pressure of 11.4 Pounds Per Square Foot,” Tech. Rep. TM X-1451, Aug 1967.

${ }^{5}$ Preisser, J. S., and Eckstrom, C. V., "Flight Test of a 40-Foot-Nominal-Diameter Disk-Gap-Band Parachute Deployed at a Mach Number of 1.91 and a Dynamic Pressure of 11.6 Pounds Per Square Foot,” Tech. Rep. TM X-1575, Aug 1968.

${ }^{6}$ Moog, R. D., and Michel, F. C., “Balloon Launched Viking Decelerator Test Program Summary Report,” Tech. Rep. CR112288, 1973.

${ }^{7}$ Cruz, J. R., and Lingard, J. S., “Aerodynamics Decelerators for Planetary Exploration: Past, Present, and Future”, AIAA Guidance, Navigation and Congrol Conference and Exhibit, Keystone, CO, (AIAA Paper 2006-6792), 2006. 
${ }^{8}$ Gallon, J. C., Clark, I. G., and Witkowski, A., "Parachute Decelerator System Performance During the Low Density Supersonic Decelerator Program’s First Supersonic Flight Dynamics Test,” Tech. Rep. 2015-2130, 2015.

${ }^{9}$ O’Farrell, C., Brandeau, E. J., Tanner, C. L., Gallon, J. C., Muppidi, S., and Clark, I. G., "Reconstructed Parachute System Performance During the Second LDSD Supersonic Flight Dynamics Test,” Tech. Rep. 2016-3242, 2016.

${ }^{10}$ O’Farrell, C., Muppidi, S., Brock, J. M., Van Norman, J. W., and Clark, I. G., "Development of Models for Disk-Gap-Band Parachutes Deployed Supersonically in theWake of a Slender Body”, 2017 IEEE Aerospace Conference, Big Sky, MT, 2017.

${ }^{11}$ Cruz, J. R., Way, D. W., Shidner, J. D., Davis, J. L., Adams, D. S., and Kipp, D. S., “Reconstruction of the Mars Science Laboratory Performance and Comparison to the Descent Simulation,” Tech. Rep. 2013-1250, 2013.

${ }^{12} Z$ umwalt, C. H., Cruz, J. R., Keller, D. F., and O’Farrell, C., "Wind Tunnel Test of Subscale Ringsail and Disk-Gap-Band Parachutes”, 34 ${ }^{\text {th }}$ AIAA Applied Aerodynamics Conference, AIAA Aviation forum (AIAA Paper 2016-3882), 2016.

${ }^{13}$ O'Farrell, C., Karlgaard, C., Dutta, S., Queen, E., Ivanov, M., and Clark, I. G., “Overview and Reconstruction of the ASPIRE Project’s SR01 Supersonic Parachute Test”. 2018 IEEE Aerospace Conference, Big Sky, MT, 2018

${ }^{14}$ O’Farrell, C., Sonneveldt, B. S., Karlgaard, C., Tynis, J. A., and Clark, I. G., “Overview of the ASPIRE Project’s Supersonic Flight Tests of a Strengthened DGB Parachute”, 2019 IEEE Aerospace Conference, Big Sky, MT 2019 (submitted for publication)

${ }^{15}$ Muppidi, S., O’Farrell, C., Tanner, C. L., and Clark, I. G., "Modeling and Flight Performance of Supersonic Disk-Gap-Band Parachutes in Slender Body Wakes”, 2018 Atmospheric Flight Mechanics Conferences, AIAA AVIATION Forum, Atlanta, GA, (AIAA 2018-3623), 2018.

American Institute of Aeronautics and Astronautics 